\title{
Rol desempeñado por el Dr. Jaime Caiceo Escudero en la creación y gestación inicial del DUOC
}

\author{
Role played by Dr. Jaime Caiceo Escudero \\ in the creation and initial gestation of the DUOC \\ Papel desempenhado pelo Dr. Jaime Caiceo Escudero \\ na criação e na implementação do DUOC
}

ESTELA SOCÍAS MuÑOZ

\section{Resumen}

Producto de la Reforma Universitaria iniciada en la Pontificia Universidad Católica de Chile en 1967, al año siguiente un grupo de estudiantes fundó el Departamento Universitario Obrero Campesino -DUOC- con el objeto de establecer un nexo entre la universidad y los obreros y campesinos chilenos; a ellos se les abría las puertas de la "torre de marfil" que era la entidad universitaria a fin de capacitarlos para el mundo laboral. Fue un importante aporte a la educación popular. En la creación y consolidación de esta institución le cupo una importante labor al profesor Jaime Caiceo Escudero. En este artículo se persigue reconstituir su vida y su formación y, especialmente, dar a conocer su participación activa en la gestación y organización de tan importante institución dedicada a la educación popular desde hace cerca de 50 años.

Palabras claves: Reforma Universitaria. Educación Popular. Capacitación Laboral. DUOC. Biografía educador chileno.

\footnotetext{
${ }^{1}$ Académica de la Universidad Mayor en Santiago de Chile. Profesora de Educación Básica con Mención en Lenguaje y Comunicación (Universidad Mayor en Santiago de Chile) y Magíster en Literatura (Universidad Adolfo Ibáñez en Santiago de Chile). Presidenta de la Academia de Literatura Infantil y Juvenil en Chile y Miembro de la Sociedad Chilena de Historia de la Educación. E-mail: estelafrancisca.socias@gmail.com
} 


\begin{abstract}
Product of the University reform initiated in the Pontifical Catholic University of Chile in 1967, the year following a group of students founded the University Department Worker Peasant-DUOC- in order to establish a link between the University and the workers and Chilean peasants; opened to them the doors of the "ivory tower" which was the University entity in order to train them for the world of work. It was an important contribution to popular education. In the creation and consolidation of this institution an important work fit to Professor Jaime Caiceo Escudero. This article is intended to rebuild his life and his training and, especially, to publicize its participation active in gestation and organization of this important institution dedicated to popular education for nearly 50 years.
\end{abstract}

Keywords: University reform. Popular education. Job training. DUOC. Chilean educator biography.

\title{
Resumo
}

Produto da Reforma Universitaria iniciada na Pontifícia Universidade Católica do Chile, em 1967, no ano seguinte um grupo de estudantes fundou o Departamento Universitário Operario Camponês - DUOC -, com o objetivo de establecer um nexo entre a universidade e os operarios e camponeses chilenos; para eles abriam-se as portas da "torre de marfim" que era a universidade, com a finalidade de capacitá-los para o mundo do trabalho. Foi um importante aporte para a educação popular. Na criação e na consolidação desta instituição desempenhou papel importante o professor Jaime Caiceo Escudero. Neste artigo objetiva-se reconstituir sua vida e sua formação, especialmente, dar a conhecer sua participacão ativa na construção e na organização de tão importante instituição dedicada à educação popular há 50 anos.

Palabras claves: Reforma Universitária. Educação Popular. Capacitação Laboral. DUOC. Biografia educador chileno. 


\section{Introducción}

A través de la historia en Chile, nos encontramos con destacados profesionales que, junto a tantas generaciones de anónimos maestros, han hecho posible que mediante sus investigaciones y desarrollo profesional han entregado a los educadores un conocimiento cabal del proceso educativo, sus principios, objetivos y orientaciones, gracias a sus publicaciones y al ejemplo de sus vidas como maestros con verdadera vocación.

En este artículo se desea reconocer y valorar el trabajo docente del Doctor en Ciencias de la Educación, Jaime Caiceo Escudero, reconstituyendo su vida y su formación y, especialmente, dar a conocer su participación activa en la gestación y organización del Departamento Universitario Obrero Campesino -DUOC-, institución creada en 1968 por tres estudiantes de la Pontificia Universidad Católica de Chile (entre ellos el profesor Caiceo), en beneficio de las personas más desposeídas de cultura y educación en ese momento histórico del país, como eran los obreros y campesinos. En el proceso de Reforma Universitaria iniciado el año anterior en la Universidad Católica se pretendía abrir la universidad a los más necesitados de la nación; justamente la fundación del DUOC fue una respuesta concreta a los principios de la Reforma. Cabe destacar que los movimientos reformistas en las universidades se iniciaron primero en Chile en 1967 y, sólo al año siguiente, se produjeron los movimientos de París. Cobra relevancia hacer esta publicación, pues en el 2018 se conmemora el cincuentenario de la fundación de la institución.

Este trabajo, es fruto de una investigación realizada en la Universidad Mayor y la metodología utilizada es la propia de los estudios históricos, recurriendo a fuentes primarias (entrevistas, revistas y libros de la época) y secundarias, ya que al abordar una temática reciente se ha dispuesto de testigos directos que han suministrado valiosa información que ha facilitado el resultado de la misma.

\section{Antecedentes biográficos de Jaime Caiceo Escudero}

\subsection{Su Infancia}

Nació en Santa María de Aconcagua, Chile, el día 21 de Mayo de 1948; sus padres fueron Manuel Caiceo Villalón, nacido el 30 de Octubre de 1904 y su madre Luisa Antonieta Escudero Osorio, nacida en 1909; ese matrimonio tuvo dos hijos, Jorge, nacido el 30 de octubre de 1944 y Jaime. Sus padres eran agricultores que vivían en una casa de campo; esa infancia provinciana y campesina, generó en el joven Jaime una cultura centrada en la disciplina y el estudio, lo que forjó en él una preocupación constante por los niños campesinos y, en general, por los niños humildes y desvalidos de su tierra natal. Su padre, además de Agricultor era Juez Repartidor de Aguas de la Primera Sección del Río Aconcagua, desde Río Blanco a San Felipe (Caiceo, 2015a). De estas experiencias junto a su padre Manuel, Jaime Caiceo expresa: 
Mi padre en su calidad de agricultor, no solo adquirió algunas tierras con su trabajo, sino que además administraba fundos a otras personas; esto fue relevante en mi caso porque desde pequeño lo acompañaba en sus labores agrícolas y viendo su ejemplo, aprendí a administrar, que ha sido mi labor principal que he realizado en mi profesión. Veía cómo dirigía y organizaba a los trabajadores en el campo, cómo los supervisaba, cómo los ayudaba en el desarrollo de sus liquidaciones de sueldos que todas las semanas en forma manual mi padre hacía los cálculos pertinentes; en un sobre les ponía el líquido a recibir para cada uno de los campesinos que trabajaban con él. Yo estaba a su lado muchas veces y le ayudaba a contar el dinero; si bien era un niño en esa época me formé con esto la idea del orden y de la de saber administrar (Caiceo, 2015a).

Jaime es casado con cinco hijos ${ }^{2}$, actualmente cuatro vivos; todos profesionales destacados, siguiendo la huella de sus padres. Actualmente tiene cuatro nietos ${ }^{3}$. Jaime Caiceo ha tenido una activa participación en Congresos; tanto en Chile como en el extranjero, destacándose en su calidad de Miembro Fundador de la Sociedad de Historia de la Educación Latinoamericana -SHELA- (1992-2003) y de la Sociedad Chilena de Historia de la Educación (1992 a la fecha). Escritor de numerosos libros, tanto de Filosofía como de Educación en general, de Historia de la Educación y de la Iglesia.

\subsection{Formación y Personalidad}

Sus estudios se iniciaron en el año 1954 en la Escuela Pública Rural tri docente en la Calle del Medio de la comuna de Santa María, actual Provincia de San Felipe; iba en calidad de oyente por la exigencia de ese tiempo que se ingresaba a los 7 años a una escuela pública.

Por razones familiares, sus padres se trasladaron a la ciudad de Los Andes en el año 1955. De esta forma, el 8 de marzo de 1955, ingresa al Instituto Chacabuco de los Hermanos Maristas; en este colegio cursó los 12 años de preparatorias y humanidades, aunque los hizo en 11, pues cursó $1^{\mathrm{a}}$ y $2^{\mathrm{a}}$ preparatoria en un año, gracias a lo que había aprendido en la Escuela Rural. En este colegio influenciado por un Hermano Marista, Luis Castillo, comenzó a hacer catequesis a una población callampa, marginal, en las riveras del Río Aconcagua. En ese lugar, durante toda su enseñanza secundaria (6 años: 1960-1965) y estando en la Universidad Católica en Santiago iba todos los fines de semana a hacer catequesis a ese lugar (1966-1967); durante cinco años con el Hno. Luis y su compañero René León; después iba solo.

Las personas que más influyeron en su vida escolar fueron los Hermanos Maristas Tomás, Aquilino, Víctor, Carlos, Gaudencio y Emeterio; éste último lo hizo amar la historia hasta la actualidad; Carlos y Gaudencio lo motivaron a la filosofía; con esta formación filosófica recibida por ellos y el bachillerato en lo mismo, lo llevó a postular a la Universidad Católica de Chile a la Carrera de Pedagogía en Filosofía (Caiceo, 2015a).

\footnotetext{
${ }^{2}$ María Antonieta, abogada; Jaime Andrés, ingeniero civil industrial; Sylvia Antonieta, fallecida a los cuatro días de nacer; Felipe Manuel, médico y José Francisco, ingeniero civil industrial.

${ }^{3}$ Catalina y Manuel, hijos de María Antonieta; Nicolás y Pedro, hijos de Felipe; José Manuel, hijo de Jaime Andrés.
} 
Respecto a la actividad cristiana hacia los más desposeídos, René León Gallardo, compañero de curso en el colegio de Jaime, expresa en una de las entrevistas recogidas durante la investigación realizada:

Creo que el motor de partida para la creación posterior del Duoc fue la educación que recibimos en el colegio, ya que considero importante expresar que en 1960, antes del Concilio, empezamos a acudir a la población Hermanos Clark, en la ribera sur del Río Aconcagua, a catequizar a los niños del lugar, a empaparnos de su realidad de vida, mísera y también generosa con nosotros, lo que fue factor importantísimo en la opción elegida por Jaime y en el despertar de su sensibilidad social... Jaime tuvo la suerte de haber nacido en un hogar lleno de valores y principios cristianos muy firmes y claros; yo era muy cercano a sus padres, ya que don Manuel fue mi padrino y compartíamos en su casa. Fue fundamental haber podido compartir con él parte de mi niñez y juventud; fue fundamental pues juntos recibimos de un religioso marista, el Hermano Luis Castillo, la semilla de la sensibilidad social que, unida a la una firme fe católica, nos hizo solidarizar desde esa época con los más desposeídos (León, 2015).

Es relevante mencionar que gracias a esta actividad, Jaime debía preparar la prédica para el mes de María; eso le permitió hablar en público con mucha facilidad. Entre estos recuerdos y características, las entrevistas a dos compañeros de su educación escolar, René León y Gabriel Moreno coinciden en los principios y el carácter estudioso de nuestro educador y son una muestra fehaciente de sus ideas y principios:

Nos conocimos en el año 1964, cuando teníamos 15 años de edad y desde ese momento fuimos compañeros de colegio en el Instituto Chacabuco de los Hermanos Maristas... Jaime ha mantenido en la trayectoria de su vida rasgos constantes que se han ido acrecentando con el tiempo: siempre fue estudioso, de muy buenos logros académicos, investigador y lector insaciable. Con sentido práctico de productividad se enfoca en un tema y no se permite divagar en múltiples tópicos (Moreno, 2015).

Jaime Caiceo rindió el bachillerato -prueba necesaria para postular a la Universidad- el año 1965, ingresando el año 1966 a la Pontificia Universidad Católica de Chile, donde obtuvo el título de profesor de filosofía, con dos votos de distinción el 7 de Enero de 1970 y Licenciatura en Filosofía, distinción máxima en 1992. También realizó un Magíster en Educación, distinción máxima, en la misma Pontifica Universidad Católica de Chile, graduándose el 30 de Enero 1980, alcanzando el año 1996 el grado de Doctor en Ciencias de la Educación, Cum Lauden en la Pontificia Universidad Católica Argentina Santa María de los Buenos Aires (Caiceo, 2015c). 
Estando cursando su carrera de pre-grado, participó como Secretario General en la directiva de la Federación de Estudiantes del Pedagógico (1968-1969) y, posteriormente fue elegido Presidente del Centro de Alumnos de Filosofía (1969), representando a la Democracia Cristiana y a los independientes, frente a una lista que era del Mapu -Movimiento de Acción Popular Universitaria, escindido del Parido Demócrata Cristino- y la izquierda marxista. Relacionado con esto, Jaime Caiceo recuerda:

Yo gané la elección y el generalísimo de la misma fue un sacerdote compañero de curso -el Pbro. Germán Álvarez-, quien aglutinó a los demás religiosos y religiosas y laicos comprometidos con el evangelio, indicándoles que yo era la persona indicada para dirigir el Centro de Alumnos de Filosofía para detener el avance marxista que en esos momentos había. En ese Centro de Alumnos propusimos la creación del Instituto de Filosofía -posteriormente se transformó en la Facultad de Filosofía-, puesto que en ese entonces era solo un Departamento en el Pedagógico; lo transformamos en un Instituto en plena reforma iniciada en el año 1967 en la Universidad Católica, lo cual permitió darle a la filosofía un nuevo estatus. El saber de la ciencia debía contrastarse con la filosofía y con la teología. Por lo mismo también teníamos relaciones con la Facultad de Teología (Caiceo, 2015b).

En cuanto a sus estudios superiores, el Hno. Yvon Rousseau, compañero de curso de Jaime en el Pedagógico, expresa:

Soy Canadiense de la provincia de Quebec; religioso de la congregación de Hermanos del Sagrado Corazón (Fundación Francesa de 1821) Al empezar mis estudios de filosofía en la Universidad Católica de Chile en el año 1966, fue el momento en que conocí a Jaime; postergué mis estudios por responsabilidades en mi congregación, retomándolos en 1979 cuanto tuve mi eximen de titulo en Diciembre de ese mismo año. Entre los años 1966 y 1969, fui compañero de Jaime. En esos años aprendí a conocerlo y apreciarlo como estudiante y como persona. En el cuarto año compartimos nuestra tesis sobre "El personalismo existencial cristiano de Nicolai Berdiaev y la educación"; era una tema que describía muy bien la persona de Jaime y su preocupación como futuro educador (Rousseau, 2015).

En la entrevista al Pbro. Fernando Tapia y a Héctor Casanueva coinciden con opiniones anteriores en el sentido de haber sido compañeros en la Pontificia Universidad Católica de Chile: 
Conozco a Jaime desde 1966 en que ingresamos a la Escuela de Educación, y con él he mantenido una amistad hasta ahora, aunque no nos vemos muy seguido; además Jaime es una persona amistosa, entusiasta, espontánea, estudiosa, íntegra éticamente hablando (Tapia, 2015).

Conozco a Jaime desde 1968. Fuimos estudiantes de la P. Universidad Católica de Chile y posteriormente trabajamos en DUOC. Con él tuve una experiencia de cooperación y amistad en función de objetivos social-cristianos; es un hombre de compromiso social, perseverancia y rigor académico... con él compartí trabajo, como miembro directivo del equipo del DUOC (Casanueva, 2015).

En este sentido es importante la entrevista realizada a don Guillermo Williamson, doctor en Educación, quien describe a Jaime Caiceo como profesor, persona de principios claros y precisos, pero siempre acogedor y comprensivo:

A Jaime lo conozco desde el año 1973 cuando era alumno de Bachillerato y Licenciatura en Educación en la Pontificia Universidad Católica de Chile. El profesor Caiceo era profesor de una asignatura que se llamaba Filosofía de la Educación. Me pareció una buena persona, un profesor que se preocupaba de dar a conocer sus ideas y pese a sus pensamientos que, en la época yo encontraba medio conservador, siempre estuvo abierto a acoger a todo el mundo, independientemente de sus ideas. Recuerdo largos debates con él por la visión de la Iglesia Católica y el papel de los laicos en ella; en ese entonces yo pertenecía a los grupos católicos de izquierda -me refiero al período 1971-1973-, cristianos por el socialismo, iglesia popular y al partido de izquierda Mapu. Jaime estaba más vinculado a la Doctrina Social de la Iglesia emergente del Concilio Vaticano II y al Partido Demócrata Cristiano, en ese entonces de oposición a la Unidad Popular, gobierno que yo apoyaba. Por este motivo discutíamos de filosofía y teología cristianas vinculadas a la historia y al contexto del momento; nos aprendimos a respetar mutuamente y a querernos en ese proceso. Es tan así que hasta hoy, hace más de 40 años, fueron esas clases un momento vivencial de aprendizaje y de formación. Es importante agregar que debido al golpe militar perdí mis trabajos en la universidad y recurrí a él, quien me acogió y me ofreció hacerme cargo de la zona oriente del DUOC en Santiago, como supervisor Académico-Administrativo, con jornada completa y un sueldo muy bueno para mis expectativas (Williamson, 2015).

Sobre su personalidad y capacidad docente, un exalumno del DUOC y luego Director de una sede, señala: 
Como persona era de carácter fuerte, con principios sólidos; un buen Docente (asistí a más de una clase donde instruía algunas materias en esa época) y con conocimientos en la áreas de Filosofía y Administración (adonde lo conocí) (Villarroel, 2015).

En un sentido similar en el plano personal, caracterizando a nuestro educador, es importante lo que corrobora Hugolino González:

Con Jaime nos conocimos en 1974, en plena dictadura, la que me había aventado desde la Región del Maule. Ambos teníamos un origen provinciano común. El de la provincia de Los Andes y yo de la de San Felipe. Después con el tiempo descubrimos algunas otras afinidades. De mi paso por DUOC los recuerdos que conservo de Jaime son gratos. A pesar de su liderazgo a ratos apabullante, arrasador, mi sentimiento es de gratitud. Me prodigó apoyo y me dispensó respeto. Muchas veces sentí su afecto y preocupación propia de la amistad. Hubo un momento en que yo decidía devolverme a Talca porque mi situación de lejanía de mi mujer e hijos pequeños hacía insostenible el permanecer en Santiago con viajes esporádicos a estar con ellos. Mi decisión era dejar DUOC sin tener algo mejor que no fuera estar con mi familia. Jaime con gran generosidad desplegó esfuerzos que, muy oportunamente, facilitaron reunir a mi familia en Santiago con una solución inesperadamente práctica y ventajosa. Fue una intervención que afirmó un nuevo rumbo a mi historia familiar (González F., 2015).

Una Coordinadora de Zona del DUOC en Santiago, Elsa Tamblay, indica algunos rasgos del educador andino:

Como rasgo de personalidad que reconozco a través del tiempo (40 años) es su invariable posición religiosa y política. Sus esfuerzos por realizar una labor trascendente desde su quehacer profesional y su sentido de la amistad (Tamblay, 2015).

Un alumno suyo en la Universidad Católica y, luego funcionario del DUOC, Julio González Matus, lo recuerda y describe así:

A Jaime lo conocí en los años 60 en la Escuela de Educación de la Pontificia Universidad Católica de Chile como Profesor Ayudante y luego como profesor en Filosofía. Caminar junto a él, como profesor, amigo y persona que sabe escuchar, atento a tender la mano sin pedir algo a cambio; es autoritario con exigencia, ayudando a crecer a los que trabajan con él; posee capacidad para anticiparse, es decir, con visión de futuro, educador en la razón y la justicia. La labor docente del profesor Caiceo es amplia, abarca desde el aula universitaria en 
diferentes universidades en Chile, Brasil y Argentina, a su rol como docente directivo en colegios de Congregaciones Religiosas, donde su labor transita en la Educación y Formación de los distintos estamentos, enfatizando la Educación Cristiana y de acurdo a un proyecto educativo establecido y respetado (González M., 2015).

\subsection{Su labor docente y profesional}

El Profesor Jaime Caiceo inició sus actividades docentes, siendo aún alumno del Instituto Chacabuco de Los Andes, realizando clases de religión entre 1960 y 1965. Posteriormente, antes de titularse como profesor de filosofía, trabajó en el Liceo Santiago, ubicado en Nataniel 1349 de la capital, clases de filosofía y psicología entre 1969 y 1974 y en el Instituto Comercial Nocturno $\mathrm{N}^{\circ}$ 1, ubicado en Argomedo 360, las mismas asignaturas entre 1969 y 1984. A su vez, ha ejercido como Director de las siguientes instituciones: Director del Liceo $N^{\circ} 1$ de la Fundación Duoc ${ }^{4}$ entre 1969 y 1970; Director del Centro Técnico Profesional N 1 de la Fundación Duoc ${ }^{5}$ entre 1971 y 1972; Director Administrativo a nivel Nacional de la Fundación Duoc ${ }^{6}$ entre 1973 y 1977; Director Académico del Centro de Formación Técnica CECADE ${ }^{7}$ desde 1983 a 1986; Director y Representante Legal del Colegio de los Sagrados Corazones del Arzobispado de Santiago entre 1990 y $1995^{8}$; Director y Representante Legal del Colegio Santa Isabel de Hungría ${ }^{9}$ de La Cisterna desde 1998 hasta el día de hoy, y Director y Representante Legal del Colegio Santa Familia ${ }^{10}$ de Santiago de Chile desde el 2000 al 2011 (Caiceo, 2015c).

En su vida profesional ha realizado asesorías a instituciones educacionales, especialmente en la elaboración del Proyectos Educativos, tanto en Santiago como en Chillán; también ha asesorado en negociaciones colectivas a colegios religiosos en Santiago y Copiapó. Otro aspecto a destacar han sido sus actividades en cursos de perfeccionamiento, dictando clases especialmente en el ámbito de la gestión y de la filosofía: En la Fide Primaria estuvo entre 1978 y 1996; en el colegio de profesores apoyó entre 1986 y 1991.

Ha tenido, además, cargos de representación de establecimientos educacionales, tales como: Miembro del Consejo Provincial de Educación de Santiago Centro en representación

\footnotetext{
${ }^{4}$ Funcionó en el Pedagógico de la Universidad Católica de Chile, ubicado en Dieciocho 102. Hoy es la Sede Padre Alonso de Ovalle del DUOC; la propiedad fue adquirida mientras el profesor Caiceo era el Director Administrativo de la institución.

${ }^{5}$ Funcionó en el antiguo Liceo Alemán, ubicado en calle Moneda; demolido por la construcción de la Avenida Norte Sur y Línea 2 del Metro.

${ }^{6}$ Las oficinas de la Dirección Ejecutiva del DUOC estuvieron ubicadas en una primera etapa en la Casa Central de la Universidad Católica de Chile y, posteriormente, en Marcoleta 50 y 54.

${ }^{7}$ Funcionó en Dieciocho 181.

8 Ubicado en Alameda 2062. Una de las capacidades del profesor Caiceo es preocuparse de las construcciones; aquí reparó la Iglesia, las salas de clases y los patios. El colegio se encontraba en muy mal estado y fue reparado y remozado enteramente.

${ }^{9}$ Ubicado en Santa Anselma 0240, La Cisterna; aquí, el profesor Caiceo continuó su afición por las construcciones y rehízo el establecimiento totalmente en su gestión inicial, inaugurando las nuevas dependencias el Ministro Sergio Bitar en 2004 (Caiceo, 2010). Preocupado de mejorar la calidad de los aprendizajes ha colocado en todas las salas equipos multimedia y pizarras interactivas.

${ }^{10}$ Ubicado en Unión Americana 151, comuna de Santiago. Este establecimiento también fue mejorado substancialmente en sus dependencias: Capilla y salas de clases, incluso se construyó una sala de música acústica. También colocó equipos multimedia en todas las salas de clases.
} 
de los Directores de Colegios Particulares entre 1991 y 1994; Miembro de la Junta Directiva Nacional de la FIDE ${ }^{11}$ entre 1992 y 1996; Miembro de la Comisión del Ministerio de Educación que elaboró la Propuesta de Políticas Nacionales para la Formación de Profesores en 1993, y Miembro Fundador, Presidente y Vice-Presidente del Consejo Directivo de la Corporación Fide de Capacitación (Corficap) entre 1994 y 1996 (Caiceo, 2015c).

También ha participado en Cursos de Perfeccionamiento como estudiante: En 1970 fue becado por la Vice-Rectoría Académica de la Pontificia Universidad Católica de Chile para realizar un curso sobre "La Educación de Adultos en Venezuela", en el Ministerio de Educación de ese país, durante el mes de mayo; en 1981 fue becado por la Embajada del Brasil, para realizar en Porto Alegre un curso sobre "Teleducación" durante 30 días (Caiceo, 2015c).

A su vez, ha recibido algunos reconocimientos por su labor educativa: En 1975 el "Diploma de Honor por el Aporte a la Educación Latinoamericana de Adultos", entregado por la Universidad de Lima y el DUOC Internacional dirigido por Francisco Tokos en Perú; en 1995 el "Diploma de Honor como Andino Destacado" en el 204 Aniversario de la Fundación de la Ciudad de Los Andes, entregado por la Ilustre Municipalidad de esa ciudad; en el 2007 el Premio "Orden al Mérito Educacional y Cultura Prof. Julio Orlando Araya" entregado por la Universidad Mayor en Santiago; en el 2008 la "Medalla Oreste Plath" entregada por la Academia de Literatura Infantil y Juvenil de Chile como un reconocimiento por los 40 años de fundación del DUOC. También aparece citado en el Diccionario International Who's Who of Intellectuals del International Biographical Centre of Cambridge, England, 9th.ed., 1992, p. 103 (Caiceo, 2015c). Sin embargo, su labor más importante como docente ha sido su labor académica en el ámbito universitario, pero ello no será abordado en este artículo.

\section{El Origen del Departamento Universitario Obrero Campesino -DUOC- y el Rol desempeñado en él por Jaime Caiceo}

\subsection{Coyuntura Histórica que Posibilita el Surgimiento del DUOC y sus fundamentos filosóficos}

Lo más significativo de la Federación de Estudiantes de la Escuela de Pedagogía de la Universidad Católica de Chile de 1968 fue la creación del Departamento Universitario Obrero Campesino -DUOC- a fines de ese año. Con esta organización se pretendía que fuera dependiente de la Escuela de Pedagogía, que luego se transformaría en la Facultad de Educación, pero el Director y futuro Decano de la época, el Presbítero Fernando Cifuentes Grez, no lo quiso. Sin embargo, el Rector de la Universidad, Fernando Castillo Velasco, impulsor de la reforma iniciada en 1967, acogió al DUOC como un programa de Rectoría y eso permitió que en marzo de 1969 iniciara sus actividades el primer Liceo Popular (Caiceo, 1980; Caiceo, 2008a).

El DUOC tiene sus inicios a mediados de los años 60 producto de la disconformidad de los universitarios con su situación de privilegios respecto a los demás estudiantes y especialmente de los obreros y campesinos (Caiceo, Navarro, 2008).

\footnotetext{
${ }^{11}$ Federación de Institutos de Educación Católicos, fundado por el R.P. Raúl Silva Henríquez en 1949; posteriormente Arzobispo de Santiago y Cardenal de la Iglesia Católica que ayudó a los perseguidos durante la dictadura militar.
} 
La crisis del mundo de esa época se expresaba también en la educación superior, que apuntaba más a la instrucción que al desarrollo del hombre pleno, más al profesionalismo que a la investigación y búsqueda de nuevas formas de cooperación para el desarrollo de los países. Tal como expresó Mannhein (1969:78) en su oportunidad: "La educación era un compartimiento porque la escuela y el mundo habían llegado a ser dos categorías opuestas más bien complementarias".

Esta crisis llegó a Chile en 1967 y, por ende, a la Pontificia Universidad Católica de Chile; ello motivó la Reforma Universitaria iniciada ese mismo año el 11 de agosto. Fruto de esta situación, y como resultado de la Reforma, se produjo el surgimiento del Departamento Universitario Obrero Campesino -DUOC-. Uno de los principios de la Reforma Universitaria sostenía que la universidad debía estar al servicio der la sociedad en la cual estaba inserta, en otros términos, que la universidad y el mundo debían estar estrechamente ligados. De esta manera, los universitarios, al entregar sus conocimientos a la sociedad, devolvían en parte el esfuerzo que hacía un país subdesarrollado como Chile para mantener las universidades. La reforma pretendía que la universidad estuviera abierta a todos los chilenos. Por otra parte, el DUOC surgió en una Universidad Católica, inspirándose los fundadores en el pensamiento humanista cristiano, reforzado por las Conclusiones del Concilio Vaticano II, de la Conferencia Episcopal Latinoamericana de Medellín y del gobierno social cristiano de Frei Montalva (Caiceo, Navarro, 2008). Por lo mismo, en los considerandos de la fundación del DUOC, se afirma: "Nuestra reflexión nos conduce a proponer una visión de la educación más conforme con el desarrollo integral, que propugnamos para nuestro continente; la llamaríamos Educación Liberadora ${ }^{12}$, esto es, lo que convierte al educando en sujeto de su propio destino" (Caiceo, Navarro, 2008: 55).

El DUOC nació como expresión real de Reforma y su primer objetivo fue lograr la integración entre la Universidad y el mundo trabajador, lo que implicó romper con la estructura tradicional de la Universidad y crear mecanismos especiales a través de los cuales los trabajadores pudieran recibir los beneficios de la Universidad. Simultáneamente, y este fue nuestro segundo objetivo, descubrimos que la educación chilena, en la que íbamos a trabajar como profesores, tenía profundas deficiencias y exigía un esfuerzo creador: de ahí empezamos a poner en práctica el concepto de 'educación permanente', que entendimos como la tarea de formar al adulto desde la educación básica o media, para llevarlo a través de grados sub-técnicos y técnicos a la Universidad Misma (Caiceo, Navarro, 2008: 41).

La idea de la creación del DUOC nace del mandato evangélico: "Id y enseñad a todas las gentes" (Mt. 28, 19). En ese contexto se puede ligar el conocimiento con la necesidad de hacer más humana la vida, captando en cada grupo una forma de progresar, ya que como dice Toffler (1999) "el conocimiento da poder". Poco a poco los argumentos harían de este centro

\footnotetext{
12 Término acuñado por Paulo Freire y asumido por los Obispos Latinoamericanos en la Conferencia de Medellín (1968).
} 
de estudios uno de las mejores ideas para poder favorecer y ayudar en las necesidades importantes de los que se formarían en él.

De esta forma, un grupo de dirigentes universitarios de la Pontifica Universidad Católica de Chile, que eran Francisco Tokos, Iván Navarro y Jaime Caiceo hacen realidad ese sueño encarnando su verdadero sentido en la frase "DUOC: el compromiso de la Universidad con el Pueblo" (Caiceo, Navarro, 2008: 28).

Por el trabajo realizado en las poblaciones marginales de Los Andes por nuestro autor, cuando era estudiante, es comprensible que asuma el rol protagónico que tuvo en la creación e inicio del DUOC.

\subsection{Primeros Liceos y Centros Técnicos del DUOC}

Cabe destacar que el Dr. Caiceo asume la dirección del Liceo Popular $\mathrm{N}^{\circ} 1$ del DUOC en 1969 y comienza sus clases el primero de abril de ese año. Los primeros alumnos provenían de dos grupos: de los sindicatos existentes en la Universidad Católica y del sindicato del Ministerio de Obras Públicas, con el cual se firmó un convenio especial. El primer liceo partió en el mismo Pedagógico de la universidad, ubicado en Dieciocho 102, con un poco más de 300 alumnos; en él se entregaba enseñanza básica y media a todas las personas que tenían sus estudios incompletos. También se firmó un convenio con el Ministerio de Educación, entidad que a fines de ese año mandó una comisión para que tomaran exámenes a los alumnos y éstos fueran validados. Esto fue posible, ya que el Subsecretario de Educación era don Ernesto Livacic, un profesor de la Pontificia Universidad Católica y muy allegado a las mismas ideas social-cristianas de los fundadores del DUOC. Este reconocimiento de los estudios permitió que rápidamente empezaran a surgir otros liceos y, al segundo año, había tres y así sucesivamente hasta llegar a más de cinco sedes en Santiago (Caiceo, 2015b).

El DUOC, como ya se indicó, perseguía abrir la universidad a las clases obreras y campesinas del país marginadas de cultura y educación. Gracias al aporte de alumnos de otras carreras, en 1970 se creó el primer Centro Técnico, el cual funcionó en el antiguo Liceo Alemán ubicado en Moneda con la actual Norte Sur, siendo el propio Jaime Caiceo su primer Director.

Había cursos de las más diversas áreas. Para las mujeres había peluquería, modas, artesanías $^{13}$; para los hombres fundamentalmente había carreras técnicas como dibujo técnico, topografía, mecánica. Este fue el inicio de una gran expansión que el Duoc empezó a tener rápidamente, porque era tal el impacto que esta política educativa impulsada por tres alumnos y, gracias al apoyo del Rector de la universidad, significó que en Santiago se llegara a tener en un plazo de cuatro años, cuarenta y cuatro sedes repartida a lo largo de los diferentes sectores de la capital.

Para poder administrar aquello, le pidieron a Jaime Caiceo Escudero que asumiera la gestión administrativa y financiera de la institución, siendo nombrado en 1972 Director Administrativo del DUOC, cargo que hoy en día se llama Vicerrector Económico y Administrativo. Se dividió Santiago en cuatro áreas: zona norte, zona sur, zona poniente y

\footnotetext{
${ }^{13}$ Posteriormente se creará en Santiago una Unidad propia de capacitación para la mujer (Caiceo, 2008b).
} 
zona oriente, nombrando un Coordinador Académico-Administrativo en cada zona. La organización administrativo-financiera de la institución significó, a su vez, que los alumnos que, en un comienzo iban gratis, empezaran a cancelar un pequeño aporte muy insignificante, pero eso posibilitó que al cabo del tercer año, los alumnos de la universidad que eran profesores en las diferentes sedes del DUOC, comenzaran a recibir un incentivo económico, fuera del incentivo académico que ya recibían por parte de la Rectoría de la universidad: créditos facultativos, válidos para sus carreras (Donoso, 1976).

También llegaban presiones de provincias y fue así como en el año 1972, el Duoc comenzó a extenderse a provincias. Primero partió el Plan Sur: Osorno, Valdivia, Puerto Montt, Chillán, Temuco, Concepción. Esto significó que al cabo de 3 años (1975) el Duoc estuviera presente desde Arica a Punta Arenas: 105 sedes conformaban la institución con centros técnicos y liceos populares a lo largo del país (Caiceo, 2009).

Con el advenimiento del régimen militar, el Rector Castillo fue depuesto y asumió como Rector Delegado de la Junta de Gobierno, el Almirante Jorge Sweet en octubre de 1973. Durante los dos primero años, él respetó la política que el DUOC tenía y durante ese periodo, a su vez, quiso darle vida jurídica a la institución. Fue así como surgió la Fundación Departamento Universitario Obrero Campesino, hoy conocida como fundación DUOC - UC.

Al mismo tiempo, se le pidió al Ministerio de Educación que se reconocieran los estudios técnicos y sub-técnicos que el DUOC estaba dando y fue así como en el mismo año 1975, gracias a la personalidad jurídica obtenida, a través del Decreto 205, el Ministerio reconoció los estudios sub-técnicos y técnicos que el Duoc entregaba. Esto es muy relevante porque será el modelo para que en 1981 el gobierno militar implementara los Centros de Formación Técnica y los Institutos Profesionales. El Duoc fue la base de aquello (Caiceo, 2009).

En cuanto a la labor profesional del profesor Caiceo en el DUOC se han recopilado entrevistas de profesionales y académicos que avalan la importancia de este trabajo del que sus huellas son palpables al leerlas, reconociendo "un trabajo serio y responsable” (Servat, 2015):

Conozco a Jaime, desde el año 1969 cuando Duoc impartía cursos Pre Universitarios y asistía a clases para preparar la Prueba de Aptitud Académica. En ese lugar logré un crecimiento, tanto personal como profesional, porque el profesor Caiceo creyó en mí para desarrollar una carrera funcionaria dentro de la institución, sin conocerme como persona cuando recién egresaba en la escuela Industrial; me ofreció trabajar en el proyecto ambicioso llamado DUOC. Jaime era una persona de carácter fuerte, con principios sólidos, un buen Docente, su aporte a favor de grandes cambios en la educación para atender a esa multitud humana deseosa de capacitarse y ofrecer la oportunidad de crecer como personas para aspirar a mejores puestos dentro de sus empresas es palpable, un sueño realizado con mucho esfuerzo. Trabajé en las sedes que se mantenían en diversos puntos de la Región Metropolitana y Regiones; me visitaba cuando cumplía el calendario de visita de sucursales en calidad de Director Administrativo y de Finanzas; las relaciones con todos eran de buen trato (Villarroel, 2015). 
Algo similar agrega el Jefe del Departamento de Servicios del Duoc durante esa época, don Luis Alfredo Cabrera:

En el DUOC fui jefe de departamento y servicios en los años 1974 1979; desde 1974 prestaba servicios al DUOC, y de ahí Jaime Caiceo me invitó a trabajar en su equipo de gestión. Fue muy importante mi ingreso en esa calidad ya que me mostró una forma de trabajo intenso, de mucha presión, pero cordial y de mucho respeto; me considero su amigo, a pesar de que no lo he visto después, más de un par de veces. Jaime era una persona trabajadora, estudiosa, con visión, directo, soñador. Se decía en esos tiempos que fue uno de los ideólogos y fundadores del DUOC, y luego que fue el gestor del desarrollo y crecimiento del proyecto (más de 100 sedes a lo largo de todo el país). Siempre lo conocí en el DUOC como Director Administrativo y mientras ocupaba ese cargo, además era profesor universitario y de una escuela de adultos nocturna (Cabrera, 2015).

\subsection{Cómo Comenzó a Funcionar el DUOC desde el Punto de Vista Administrativo- Financiero}

Don Jaime Caiceo Escudero asumió la dirección administrativo-financiera del DUOC -tal como ya se indicó- cuando éste se había comenzado a extender a todo Chile; ello fue a partir del año 1972. Primeramente comenzó el trabajo sólo con 4 personas; ellas fueron:

* Mauricio Mazo Figueroa, quien fue el brazo derecho de don Jaime en la tesorería de la institución; con él abrieron las cuentas corrientes y giraban los recursos.

* Antonio Alday Zamora, quien fue uno de los primeros ayudantes de auditoría que tuvo para la revisión contable que se realizaba en todas las sedes a lo largo de Chile.

* Eduardo Rojas Salgado, quien era el secretario adjunto y que estaba siempre al lado de don Jaime tratando de colaborar en la resolución de problemas que fueran apareciendo.

* Rosa Barrios fue su primera secretaria y colaboró lealmente con su Director Administrativo Financiero (Caiceo, 2015b).

Según las propias palabras, en una entrevista, el Dr. Caiceo, recuerda:

Lo más relevante, desde el punto de vista administrativo-financiero fue establecer un Manual de Procedimientos Administrativos, Contables y Financieros para todas las sedes del país. Para ello tuve la asesoría de una organización de auditores titulados en la Facultad de Administración y Economía de la Universidad Técnica del Estado UTE-, hoy Universidad de Santiago de Chile -USACH-: Juan Carlos Ortiz y Pedro Berrios, quienes eran ejecutivos de ACAL (empresa auditora). Ellos colaboraron con la organización y conmigo para establecer ese primer Manual de Procedimientos y el Plan de Cuentas, 
necesarios para funcionar. Junto a ellos, hubo 2 personas adultas (los 4 que nombré antes eran jóvenes igual que yo): ellos fueron estrechos colaboradores en la instauración de la Dirección Administrativa del DUOC; ellos eran, don Jorge Gilbert Ossandón y don Jorge Sepúlveda (Caiceo, 2015b).

Para poner en práctica el Manual de Procedimientos se realizó una Jornada en Punta de Tralca -distante $130 \mathrm{kms}$. de la capital- con todos los Directores y Secretarios Administrativos de las diferentes Sedes del DUOC.

En esas jornadas se interiorizó toda la gente de sus roles y funciones; se estableció, por sistemas de control interno y de seguridad que, salvo las cuentas de Chiloé, Aysén y Magallanes -que funcionaban con el Plan Austral ${ }^{14}$, en que los recursos los manejaba el director de cada sede con don Jorge Gilbert-, todas las demás sedes del país debían depositar todos los días los recursos recaudados el día anterior a la cuenta corriente central del DUOC en Santiago (Caiceo, 2015b).

Se eligió esta medida centralizadora de los recursos para familiarizar a los funcionarios en su labor, considerando que, salvo excepciones, no eran personas formadas en el área contable. Esta medida se mantuvo desde 1973 hasta 1975, año en que se establecieron las zonas por regiones (5 en total en el país): Antofagasta ${ }^{15}$, Valparaíso ${ }^{16}$, Talca ${ }^{17}$, Concepción ${ }^{18}$ y Puerto Montt ${ }^{19}$. Cada zona tenía un Coordinador que manejaba sus recursos, rindiendo a la Dirección General. Los recursos de las 44 Sedes de Santiago eran manejados centralizadamente.

De esta forma se manejaban los recursos administrativos $y$ financieros. Pero, al mismo tiempo, a todos los funcionarios se le hizo contrato de trabajo a partir de 1975, cuando el DUOC logró su personalidad jurídica como Fundación Departamento Universitario Obrero Campesino. De esta forma, se regularizó la parte financiera y administrativa del DUOC y la gestión de personal. Respecto de las adquisiciones, muchas se hacían a nivel central, pero se le pedía a cada sede que llevara un inventario de los bienes que recibía.

\footnotetext{
${ }^{14}$ El Senador Juan Hamilton que representaba a las entonces Provincias de Chiloé, Aysén y Magallanes extremo Sur del país-, logró a través de una ley de su autoría que la Corporación de Fomento -CORFO-, entidad pública, entregara el 2\% de sus recursos al DUOC de las respectivas Provincias. Esos fondos debían rendirse a la Contraloría General de la República y eran administrados en cada Sede, siendo supervisados por el Sr. Jorge Gilbert, quien hacía las rendiciones pertinentes. A ello se le denominó Plan Austral.

${ }^{15}$ Abarcaba desde Arica hasta Vallenar y la dirección la ejercía Julio González Matus.

${ }^{16}$ Abarcaba desde la Serena hasta San Antonio y la gestión la desempeñaba Enrique Molina.

${ }^{17}$ Abarcaba desde Rancagua hasta Linares y cuyo responsable era Fernando Satelices Céspedes.

${ }^{18}$ Abarcaba desde Concepción hasta Temuco y era manejada por Alonso Núñez Lamas.

${ }^{19}$ Abarcaba desde Valdivia a Puerto Montt, cuyo Coordinador era el señor Uribe.
} 
Esta fue la manera cómo se logró echar las bases administrativas y financieras del DUOC y, tal como lo desarrollé en mi tesis de Magister en Educación (1980), se pasó de una estructura organizacional simple a una estructura organizacional compleja. Ello se debía al crecimiento significativo que año a año la institución tenía y la complejidad que implicaba tener tantas sedes en tantos lugares: 105 sedes de Arica a Punta Arenas al año 1975 (Caiceo, 2015b).

Siguiendo con las entrevistas, que son parte fundamental en este trabajo de investigación, una estrecha colaboradora en los Departamentos de Tesorería, Contabilidad y Encargada de las Rendiciones de Cuenta a Contraloría General de la República desde octubre de 1973 al 28 de Diciembre 1977, Mónica Herrera, expresa respecto a nuestro autor, enfatizando su liderazgo, fuerza y siempre preocupado de enseñar a sus colaboradores:

Estoy muy agradecida con el Prof. Caiceo por haberme brindado la oportunidad de ingresar al ámbito laboral, siendo aún una estudiante de Pedagogía en Matemáticas y en circunstancias tan especiales como las vividas el año 1973. Compartir con él fue sentar un precedente en mi vida personal, en el sentido que cuando se cree en un proyecto como el de la magnitud del DUOC, todo es posible si se aúnan fuerzas, conocimientos e ideales. Aprendí mucho con él y su trabajo en el DUOC lo califico como brillante; en su calidad de Director Administrativo, logró mantener por tantos años a lo largo y ancho del país, tantas sedes funcionando, en donde fueron acogidas cientos y miles de personas de todas las condiciones, como también aquellas que encontraron una puerta donde cumplir sus sueños de escolaridad truncados (Herrera, 2015).

\subsection{Activa Participación de Jaime Caiceo Escudero en la formación del DUOC}

Respecto a este punto es importante señalar lo que el doctor Caiceo recuerda en la entrevista realizada para llevar a efecto esta investigación:

Iván Navarro, Francisco Tokos y el que habla, propusimos desde la Federación de Estudiantes una serie de medidas, en el contexto de la Reforma Universitaria..., pero lo más significativo fue la creación del Departamento Universitario Obrero Campesino -DUOC- a fines de 1968 (Caiceo, 2015b).

Respecto a lo indicado por el profesor Caiceo y, que ratifica sus dichos, es relevante señalar lo que exponen en las entrevistas realizadas a personas que compartieron con él en la formación del DUOC y, posteriormente, en el trabajo que efectuaron en esa Institución y el reconocimiento de su labor. A continuación se presentan las más relevantes, precisando las áreas de trabajo: 
- Subalterno directo en la gestión administrativa:

A Jaime lo conocí en 1973 en el DUOC. En varios momentos de mi permanencia allí encontré el apoyo fraterno y comprensivo, que hasta el día de hoy es recordado con profundo afecto por mi familia y que me ha llevado a replicar en otras personas el ejemplo que él me dio: las ideas primordiales en el formar una Iglesia que se acercara a los más desposeídos en el contexto de los 60 del siglo pasado, post Concilio Vaticano II y Conferencia Episcopal Latinoamericana de Medellín. Creo que la creación del DUOC fue inspiración de ese Concilio, en que los fundadores -entre ellos Jaime-, eran impulsados por un cristianismo militante que los obligaba como católicos a llegar a los pobres, no sólo llevando un mensaje esperanzador, sino que además, entregándoles herramientas que les permitiera salir de la pobreza. Conocí, a su vez, su tarea de Director Administrativo en la Fundación DUOC. Estaba permanentemente interesado en todas las áreas de la institución, siempre dispuesto a colaborar u aportar con soluciones. Colaboré estrechamente con él como Encargado de Adquisiciones y Jefe de Personal (Farrán, 2015).

- Director de Sede en Santiago:

Jaime realizó el sueño de favorecer a los más desposeídos mediante la creación del DUOC, con el fin de que pudieran capacitarse y darles la oportunidad de crecer como personas, a fin de poder aspirar a mejores puestos dentro de sus trabajos. Las relaciones en el ámbito laboral con él fueron de buen trato, con amabilidad, cordialidad y constantemente buscando mejoras en los controles técnicos, administrativos y/o pedagógicos; abarcaba todos los ámbitos que fuesen necesarios (Villarroel, 2015).

- Coordinadora Académico-Administrativa:

A Jaime lo conocí cuando ingresé al DUOC en 1974 y asumí el cargo de Coordinadora zona Central-Oriente. Producto de las visitas a las 13 sedes a cargo, debía informar y proponer soluciones, al área académica y administrativa, respecto a las necesidades que manifestaban los directivos de cada sede. Reconozco en el Sr. Caiceo una especial habilidad en el manejo del área de administración y finanzas, como también, una envidiable memoria... En cuanto al trabajo que realizó en el DUOC -mientras fue Departamento Universitario Obrero Campesino- fue trascendente y significativo para miles de personas que pudieron mejorar su calidad de vida a través de lo que ofreció el DUOC para terminar sus estudios o aprender un oficio o carrera técnica (Tamblay, 2015). 
- Directores de Sedes de Provincias, Arica y San Antonio ${ }^{20}$.

Es de gran importancia estos testimonios porque no sólo avalan la importancia de Jaime Caiceo en los orígenes y primeros años del DUOC sino que también en cuanto al carácter religioso y de compromiso social que poseía:

Conocí a Jaime en el año 1974 y me fue presentado en Santiago por el Pbro. Juan Bagá, Director Nacional del DUOC. Fue el momento en el que me hice cargo de crear la sede de Arica de la Institución. El haber compartido con él parte de su vida fue una afirmación de mis principios y valores, una oportunidad para desarrollar mi vocación profesional y adentrarme en el mundo de la educación popular. Jaime era un hombre de convicciones, de una notable capacidad de gestión, muy creativo. En cuanto a la creación del DUOC, Jaime, junto a otros precursores, fue un elemento significativo en la construcción de una Iglesia terrenal, vinculada fuertemente a la base social. En cuanto a su trabajo era eficiente, como segundo hombre de la institución le correspondió un papel preponderante en la administración del sistema y en la proyección nacional de la institución. En cuanto al rol que ha desempeñado el profesor Caiceo, puedo señalar que se ha destacado por su creatividad intelectual, además, por su alta valoración de la participación de la gente (Leblanc, 2015).

Conozco a Jaime desde el año 1972. Mi relación con él fue ejecutiva y económica: fui Director de la sede DUOC San Antonio, y mi contacto con él comienza cuando fui llamado por el Cardenal Raúl Silva Henríquez para hacerme cargo de la escuela de San Antonio y fundar la sede DUOC en esa ciudad. De Jaime aprendí que la mística era esencial para lograr los objetivos propuestos, aprendí la tolerancia, necesaria para entender que el otro también era persona. Jaime era un hombre sencillo, lleno de humanismo, trabajador, comprometido con el proyecto cristiano, de hacer una transformación educacional con el compromiso de la Universidad Católica con el pueblo, sobretodo en una tarea tan transformadora como dar capacitación a miles de estudiantes de muy escasos recursos. Jaime creyó siempre en lo que hacía y así lo hacía saber, en sus mensajes, como Director Administrativo y Económico del DUOC. Es relevante agregar que el profesor Caiceo participaba muy activamente en la Iglesia Católica, junto al Pbro. Juan Bagá, impregnando al DUOC de los cambios que eran exigidos por la Reforma Universitaria: Abrir las puertas para que ingresara aire nuevo, que fue la política de rector Fernando Castillo Velasco, que ayudó mucho. Fue la época de grandes transformaciones

20 Con la vuelta a la democracia en 1990, los Directores del DUOC, Luis Leblanc y Sergio Velasco fueron elegidos diputados de la República por sus respectivas zonas; de ahí la importancia de su testimonio. 
sociales, educando a miles de campesinos, trabajadores, mujeres y jóvenes. Fue hacer carne las directrices del Concilio Vaticano II y Medellín en el DUOC. Fue una solución de capacitación popular inédita que abrió los horizontes a miles de estudiantes de distintas edades para superar la pobreza. Más que un jefe fue un amigo, consejero, recto, transparente, paciente, humano y servicial. Ejecutivo sin trabas, dejaba hacer a los demás con absoluta confianza en el DUOC. Fue el Director Administrativo y Económico y profesor en cátedra de filosofía de la universidad (Velasco, 2015).

- Importante es precisar el rol que jugó Jaime Caiceo en el desarrollo del

Plan Campesino del DUOC (Caiceo, 2006). Al respecto, el Director del Programa de Capacitación Campesina, recuerda:

Mi relación con Jaime Caiceo fue en los hechos directa $\mathrm{y}$ significativa. No hubo una relación de interdependencia jerárquica muy próxima; sin embargo, desde su posición de Director Nacional Administrativo de DUOC nuestros intercambios fueron de alta significación. Mi responsabilidad en el Proyecto de Capacitación Campesina que procuraba abrirse paso en una Institución orientada a sectores populares urbanos y que ahora se dirigía hacia el sector campesino, necesitaba de un impulso, una fuerza más gravitante que legitimara su presencia como preocupación, ahora por los pobres del sector Rural, ello tuvo en Jaime Caiceo un gran aliado. Un formidable aliado que con su mayor comprensión del mundo rural, el que él sí conocía, acogió las directrices más gruesas que procuré imprimirle al programa que financiado por la Inter American Foundation -IAF-, requería como contrapartida local de un muy atinado y eficaz desarrollo.

Jaime, poseedor de un liderazgo audaz y pragmático, contribuyó fuertemente para allanar el camino, no exento de dificultades, a este programa que venía a legitimar la letra " $C$ " del DUOC (Departamento Universitario Obrero Campesino), pero que la lógica administrativa burocrática vigente no favorecía su desenvolvimiento (González F., 2015).

\subsection{Aprobación de los Estatutos del DUOC por parte del Estado}

El 11 de septiembre de 1973, por la interrupción de la democracia chilena por el golpe militar, el proceso de la obtención de la Personalidad Jurídica para el DUOC, iniciado en el Consejo Superior de la Pontificia Universidad Católica de Chile en agosto de ese año, quedó en suspenso. Al asumir la Rectoría, en calidad de Delegado de la Junta Militar, en octubre de ese año, el Vicealmirante Jorge Swett Madge, designó al Vice-Rector Académico, Jaime del 
Valle Allende y a Alberto Hardenssen para que junto a la Dirección Ejecutiva del DUOC (Director General, Director Académico y Director Administrativo) elaboraran los Estatutos de la Fundación DUOC. El 28 de diciembre de ese mismo año, el Rector Swett firmó los Estatutos de la Fundación Departamento Universitario Obrero Campesino - DUOC- de la Pontificia Universidad Católica de Chile para que se iniciaran los trámites legales en el Ministerio de Educación y en el Ministerio de Justicia, a fin de obtener la personalidad jurídica. El Rector Swett en diciembre de 1974 dirá:

Al llegar en octubre del año pasado a esta Universidad para asumir la responsabilidad de dirigir como Rector-Delegado del Gobierno esta Casa de Estudios, una de las actividades que más me llamó la atención fue la del DUOC. Un organismo dependiente de una Universidad, pero que no es Universidad, sino que bajo la tutela de ella lleva la cultura y educación a nuestro pueblo: Al empleado, al obrero, al campesino y a la dueña de casa.

Sin embargo, a pesar de la admiración que el DUOC me despertó el año pasado, había algo que me preocupaba: La existencia legar de este inmenso Organismo Educacional. Por ello, personalmente me preocupé de buscarle, en conjunto con las autoridades universitarias y las del DUOC, una solución a su existencia irregular (Swett en Caiceo, Navarro, 2008: 72).

El 30 de octubre de 1974 se aprobó el Decreto que otorgó Personalidad Jurídica a la Fundación DUOC por parte del Ministerio de Justicia: Se publicó en el Diario Oficial con el $\mathrm{N}^{\circ} 1.381$ el 22 de noviembre de ese mismo año.

Complementario a lo anterior, se encuentra la aprobación del Decreto 205 de 1975 por parte del Ministerio de Educación que reconoció como válidas las carreras sub-técnicas y técnicas del DUOC. Esta situación es muy relevante para el desarrollo de la educación superior en Chile, pues esas carreras y el DUOC como institución, servirán de modelo para la creación en 1981 de los Institutos Profesionales (Decreto 5) y Centros de Formación Técnica (Decreto 24), ambos decretos dictados por el Ministerio de Educación, a fin de reformular la Educación Superior en el país, quedando constituida a partir de ese año por las Universidades, Institutos Profesionales y Centros de Formación Técnica. Hoy el antiguo DUOC se le menciona como DUOC-UC y es un Instituto Profesional y un Centros de Formación Técnica.

\subsection{Funcionamiento Central del DUOC}

En su primera etapa (tres primeros años) existía un triunvirato que ejercía la Dirección como Coordinación Central; estaba integrado por Iván Navarro, Francisco Tokos y el Pbro. Juan Bagá Ballús. A partir de 1972, el DUOC funcionaba a nivel central con un consejo integrado por el Director Ejecutivo, Pbro. Juan Bagá; por un Director Académico, Horacio Marín García; un Director Administrativo, Jaime Caiceo Escudero, y un Secretario General, Horacio Villarino Goldsmith. Este consejo funcionaba normalmente todas las semanas; todos ellos eran los responsables del DUOC ante la Rectoría de la Universidad Católica. Sin embargo, al establecerse la fundación, se estableció que la máxima autoridad de la institución era el Rector de la Universidad, quien tendría un consejo compuesto por las cuatro personas 
nombradas anteriormente, más el Rector de la Pontificia Universidad Católica de Chile, que lo presidía, el Vicerrector Académico de la universidad, el Vicerrector Administrativo de la universidad y el Vicerrector de Comunicaciones. Este Consejo General del DUOC funcionaba todos los meses y era a ese organismo que había que estarle rindiendo cuentas de la institución (Caiceo, 2015).

Por otra parte, Jaime Caiceo recuerda que el Pbro. Juan Bagá recorría organismos europeos y norteamericanos que aportaban aportes para el DUOC en general -ello ayudó para comprar la ex Casa García, por ejemplo, en donde hoy funciona una importante sede de la institución en Alameda con Av. España- o para proyectos específicos -Plan Campesino y Plan de Capacitación para la Mujer-.

De esa manera, el DUOC continuó su funcionamiento; sin embargo, el gobierno militar no veía con buenos ojos que existiera una institución por todo Chile entregando educación, capacitación y perfeccionamiento a jóvenes, mujeres y campesinos y le solicitó al Rector Swett que fuera eliminando sedes en Provincias. De esta forma la institución comenzó a reducirse en regiones y ello posibilitó que instituciones privadas formadas por ex funcionarios del DUOC, continuaran con tal labor en Regiones, pero centrándose sólo en los jóvenes. De esta forma, el DUOC quedó reducido sólo a Valparaíso, Viña, Concepción, Talcahuano y Santiago; todas las demás sedes de las regiones fueron cerradas (Caiceo, 2015b).

El equipo inicial del DUOC no aceptó la nueva decisión tomada en el gobierno y en la Dirección Superior de la Universidad, lo cual trajo roces y desavenencias entre los mismos directivos del DUOC y entre ellos y las autoridades universitarias, lo cual significó que a fines de 1977, el Rector Swett decidiera cambiar el equipo directivo de la institución, asumiendo como nuevo Director Ejecutivo, Gilberto Zárate Barrera (Caiceo, 2015b).

\section{Conclusiones}

Según los antecedentes investigados en este estudio, se puede concluir:

1) El origen del Departamento Universitario Obrero Campesino está inspirado en la doctrina social cristiana de la Iglesia Católica post conciliar y surge en la Pontificia Universidad Católica de Chile por tres estudiantes del Pedagógico de esa universidad, uno de los cuales es Jaime Caiceo. Su objetivo es entregar educación a los más necesitados en el contexto de la Educación Popular.

2) En las entrevistas realizadas, la opinión generalizada indica que Jaime Caiceo tuvo un rol preponderante en la organización de la institución y en el manejo financiero de la misma, en el apoyo a la extensión de sedes a Provincias y en la instauración del Plan Campesino. A su vez, varios de los entrevistados, señalan que su accionar iba más allá de su cargo de Director Administrativo, transformándose en el ejecutor de la política de la institución.

3) La acción desarrollada por nuestro educador obedece a su profunda concepción religiosa, muy católica, que se manifiesta tanto en el ámbito familiar como en el profesional.

4) El accionar del profesor Caiceo va más allá del simple hacer, pues su trayectoria está plasmada en libros y artículos que ha publicado, tanto en Chile como en el extranjero. En esos escritos ha quedado plasmada su perspectiva educacional, en donde sistematiza su pensamiento como un educador cristiano que ha sido capaz de poner en práctica en los lugares donde se ha desarrollado en el día a día, como ha quedado explicitado por el rol desempeñado en el DUOC. 


\section{Referencias}

\section{a) Libros y Revistas}

DONOSO, Sebastián et al. (1976). Informe sobre el Área Administrativa de la Fundación DUOC. Santiago de Chile: CIDE.

CAICEO, Jaime (1980). El Desarrollo Estructural de una Organización Educacional No Formal: Caso Estudio Fundación DUOC, en su Primera Década de Existencia: 1968 - 1978. Santiago de Chile: Tesis para optar al Grado de Magister en Educación, Pontificia Universidad Católica de Chile, 458 pp.

CAICEO, Jaime (2006). "El DUOC y su Aporte a la Educación de los Obreros y Campesinos Chilenos Durante la Primera Década de Existencia (1968-1978)". Revista de Educação, No 20, junho, PUC - Campinas, Brasil, pp. 121/136.

CAICEO, Jaime (2008a). "Los Orígenes del Departamento Universitario Obrero Campesino DUOC- de la Pontificia Universidad Católica de Chile". Perspectivas Educacionales, $\mathrm{N}^{\mathrm{o}} 8$, Universidad Metropolitana de Ciencias de la Educación, Santiago de Chile, pp. 13/32.

CAICEO, Jaime (2008b). "El Departamento Universitario Obrero Campesino -DUOC- y su Aporte a la Educación de la Mujer Pobladora y Campesina durante la década del 70, del siglo pasado, en Chile". El Pajar. Cuaderno de Etnografía Canaria, II Época, № 25, agosto. Islas Canarias, España: Asociación Cultural "Pinolere, Proyecto Cultural", pp. 182/187.

CAICEO, Jaime (2009). "El DUOC como expresión de la Educación Popular en la Década del 60 en Chile". Cadernos de História da Educação, Vol. 8, № 2, Julho a Dezembro ISSN: 1982-7806, Universidade de Uberlândia, Brasil, pp. 313/326.

CAICEO, Jaime; NAVARRO, Iván (2008). DUOC: Un Sueño Estudiantil Hecho Realidad. Santiago de Chile: Patrocinado por la Vicaría de la Pastoral Social y de los Trabajadores. Avales Académicos: Pontificia Universidad Católica Argentina y Sociedad Chilena de Historia de la Educación, Imprenta Madrid, 156 pp.

MANNHEIM, Karl (1969). Diagnóstico de nuestro tiempo. México: Ed. Trillas.

NACAR, Eloino; COLUNGA, Alberto (1944). Sagrada Biblia. $1^{a}$ edición. Madrid: Biblioteca de Autores Cristianos -B.A.C.--

TOFFLER, Alvin (1999). El Cambio del Poder. Barcelona: Plaza \& Janés Editores S.A.

\section{b) Entrevistas}

CABRERA, Alfredo (2015). Entrevista. Licenciado en Ciencias Económicas. Cargo en el DUOC: Jefe Departamento de Servicios. Fecha de permanencia: 1974-1979. Realizada en Santiago de Chile el 3 de agosto.

CAICEO, Jaime (2015a). Entrevista. Profesor de Filosofía y Doctor en Ciencias de la Educación. Miembro fundador del Departamento Universitario Obrero Campesino -DUOC- a fines de 1968. Asume la Dirección Administrativo-Financiera a partir del año 1972 hasta 1977. Realizada en Santiago de Chile el 22 de junio. 
CAICEO, Jaime (2015b). Entrevista. Realizada en Santiago de Chile el 25 de julio.

CASANUEVA, Héctor (2015). Entrevista. Máster Profesional en Comunidades Europeas. Cargo en DUOC: Vice-Coordinador General del DUOC Internacional. Fecha de permanencia: Marzo 1969-septiembre 1973. Realizada en Santiago de Chile el 14 de julio.

FARRÁN, Luis (2015). Entrevista. Técnico en Administración de Empresas. Cargo en DUOC: Jefe Departamento de Personal y Jefe Departamento de Adquisiciones. Fecha de permanencia: 1973-1980. Realizada en Santiago de Chile el 20 de mayo.

GONZÁLEZ FERREIRO, Hugolino (2015). Entrevista. Profesor, Psicopedagogo, Mediador Familiar. Cargo en el DUOC: Director del Plan Nacional de Capacitación Campesina. Fecha de permanencia: 1974-1982. Realizada en Santiago de Chile el 22 de septiembre de 2015.

GONZÁLEZ MATUS, Julio (2015). Entrevista. Magíster en Educación. Cargo en DUOC: Coordinador Regional en Antofagasta. Fecha de permanencia: 1972-1980. Realizada en Santiago de Chile el 27 de mayo.

HERRERA, Mónica (2015). Entrevista. Estudios de Pedagogía en Matemáticas. Cargo en DUOC: Administrativa en Departamento de Tesorería y Contabilidad; Encargada de Rendiciones de Cuenta a Contraloría General de la República. Fecha de permanencia: 19731977. Realizada en Santiago de Chile el 14 de julio.

LEBLANC, Luis (2015). Entrevista. Trabajador Social y Magister en Educación. Cargo en DUOC: Director sede Arica. Fecha de permanencia: 1974-1980. Realizada en Arica, Chile el 14 de julio.

LEÓN, René (2015). Entrevista. Meteorólogo. Compañero de curso en el colegio de Jaime Caiceo. Realizada en Los Andes, Chile el 8 de julio.

MORENO, Gabriel (2015). Entrevista. Profesor de Educación General Básica. Compañero de curso en el colegio de Jaime Caiceo. Cargo en DUOC: Inspector General de la Sede de Artes. Fecha de permanencia: 1974-1980. Realizada en Santiago de Chile el 17 de mayo.

ROUSSEAU, Yvon (2015). Entrevista. Profesor de Filosofía. Compañero de curso en la Universidad de Jaime Caiceo. Realizada por vía electrónica a Canadá el 5 de junio.

SERVAT, Berta (2015). Entrevista. Socióloga y Doctora en Ciencias de la Información y Comunicación. Cargo DUOC: Especialista en Educación. Fecha de permanencia: 1975-1976. Realizada en Santiago de Chile el 13 de julio.

TAMBLAY, Elsa (2015). Entrevista. Profesora Primaria y Especialista en Administración Educacional. Cargo en DUOC: Coordinadora Académica Zona Central Oriente, Santiago; Jefe Departamento de Programas Regulares; Jefe Departamento de Admisión y Registro Curricular. Fecha de permanencia: 1974-1985. Realizada en Santiago de Chile el 27 de mayo.

TAPIA, Fernando (2015). Entrevista. Profesor de Filosofía y Sacerdote. Compañero de curso en la Universidad de Jaime Caiceo. Realizada en Santiago de Chile el 27 de mayo.

VELASCO, Sergio (2015). Entrevista. Profesor y ex Diputado. Cargo en DUOC: Director sede San Antonio. Fecha de permanencia: 1972-1981. Realizada en San Antonio, Chile el 24 de mayo. 
VILLARROEL, Alejandro (2015). Entrevista. Egresado Construcción. Cargo en DUOC: Secretario, Inspector General y Director Sede Universitario Salvador. Fecha de permanencia: 1970-1977. Realizada en Santiago de Chile el 20 de mayo.

WILLIAMSON, Guillermo (2015). Entrevista. Doctor en Educación. Cargo en DUOC: Supervisor Académico-Administrativo. Fecha de permanencia: 1974-1978. Realizada en Temuco, Chile el 25 de mayo.

c) Otros

CAICEO, Jaime (2015c). Curriculum Vitae. Entregado por el interesado a la autora de la investigación. Figura, a su vez, en los archivos de la Universidad de Santiago de Chile. 